\title{
Optical properties of lead-bismuth cuprous glasses
}

\author{
P T DESHMUKH $\#$, D K BURGHATE*, $V$ S DEOGAONKAR, S P YAWALE ${ }^{\dagger}$ and \\ S V PAKADE ${ }^{\dagger}$ \\ Department of Physics, Shri Shivaji Science College, Amravati 444 603, India \\ ${ }^{\dagger}$ Department of Physics, Government Vidarbha Institute of Science and Humanities, Amravati 444 604, India \\ ${ }^{\#}$ Department of Chemistry, Dr Panjabrao Deshmukh Polytechnic, Amravati 444 603, India
}

MS received 28 April 2003; revised 11 August 2003

\begin{abstract}
The optical transmission and absorption spectra in UV-VIS were recorded in the wavelength range 350-800 $\mathrm{nm}$ for different glass compositions in the system $(\mathrm{CuO})_{x}(\mathrm{PbO})_{50-x}\left(\mathrm{Bi}_{2} \mathrm{O}_{3}\right)_{50}(x=2 \cdot 5,5 \cdot 0,7 \cdot 5$, 10.0, 12.5, 15.0, 20.0). Absorption coefficient $(\alpha)$, optical energy gap $\left(E_{\text {opt }}\right)$, refractive index $\left(n_{\mathrm{D}}\right)$, optical dielectric constant $\left(\varepsilon_{\infty}^{\prime}\right)$, measure of extent of band tailing $(\Delta E)$, constant $(\beta)$ and ratio of carrier concentration to the effective mass $(\mathrm{N} / \mathrm{m} *)$ have been reported. The effects of compositions of glasses on these parameters have been discussed. It has been indicated that a small compositional modification of the glasses lead to an important change in all the optical properties including non-linear behaviour. The optical parameters were found to be almost the same for different glasses in the same family.
\end{abstract}

Keywords. Optical properties; lead bismuth glasses; non linear behaviour.

\section{Introduction}

In recent years, the interest in the study of electrical, optical and structural properties of glassy semiconductors has increased considerably (Mandal and Ghosh 1993). The frequency dependent dielectric and optical properties of binary semiconducting glasses in the system $\mathrm{V}_{2} \mathrm{O}_{5}-\mathrm{TeO}_{2}-$ $\mathrm{PbO}$ have been measured as a function of lead content and the effects of composition on refractive index, dielectric constant and optical phonon frequency have been discussed by Memon et al (1993). The non-linear optical properties of $\mathrm{B}_{2} \mathrm{O}_{3}$ based glasses have been reported by Kentaro et al (1995). The effect of iron on the optical, physical and structural properties of several iron phosphate and sodium iron phosphate glasses were investigated by using X-ray photoelectron spectroscopy (XPS), Mössbauer spectroscopy and IR by Guomei et al (1994).

Optical properties and chemical durability of leadindium-aluminium phosphate glasses prepared by a wet chemical process have been investigated by Gongyi and Yuli (1993).

Refractive index is an important parameter for the design of optical components such as prism, windows and optical fibre (Ma et al 1993). The electrical and optical studies of $\mathrm{Cr}^{3+}$ doped chlorophosphate and phosphate glasses were carried out at low doping concentration by Bishnoi et al (1993). The work on optical and non-linear optics was reported by Janewicz et al (1993). Burghate et al (1995) reported optical properties of lead bismuth tita-

\footnotetext{
*Author for correspondence
}

nate glasses and lead bismuth glasses. The effect of composition of glasses on these optical parameters have been discussed.

Linear and non-linear optical properties of chalcogenide glass were investigated by Hajto et al (1993). Very little work appears to have been done on the optical properties of oxide glasses. Therefore, it has been decided to study the optical parameters of these glasses. The intention to study the optical properties of these glasses by UV-VIS spectra is to investigate the existence of localized states near band edge.

\section{Experimental}

\subsection{Preparation of samples}

Glass samples under investigation were prepared in the laboratory by mixing appropriate amounts of $\mathrm{Bi}_{2} \mathrm{O}_{3}, \mathrm{CuO}$ and $\mathrm{PbO}(\mathrm{mol} \%)$, all AnalaR grade chemicals. A homogeneous mixture of powders was prepared and fired in a fireclay crucible at $1000 \pm 10^{\circ} \mathrm{C}$ for $30 \mathrm{~min}$ in an automatically temperature controlled muffle furnace. The glass samples were then formed by quenching the melt on a steel plate held at room temperature. The X-ray diffractograms of all the glass samples were determined at the Regional Sophisticated Instrumentation Centre, Nagpur. The absence of peaks in the X-ray diffractograms confirmed the amorphous nature of the glass samples.

\subsection{Theory}

The absorption ' $A$ ' and transmittance ' $t$ ' of the glass samples were measured by means of CARY-2390 double 
beam automatic scanning spectrophotometer (Regional Sophisticated Instrumentation Centre, Chennai) in the spectral range $350-800 \mathrm{~nm}$ at normal incidence. The spectral dependence of both ' $A$ ' and ' $t$ ' on composition of the glass is shown in figure 1 .

The optical absorption coefficient, $\alpha(v)$, at the given frequency $(v)$ is given by

$$
\alpha(v)=\frac{4 \pi \sigma_{\min }}{C n_{\mathrm{D}} \Delta E} \frac{\left(h v-E_{\mathrm{opt}}\right)^{r}}{h v},
$$

where $\sigma_{\min }$ is the extrapolated d.c. conductivity at $T=\infty$, $n_{\mathrm{D}}$ the refractive index, $C$ the velocity of light, $E$ the measure of the extent of band tailing, $h v$ the photon energy, $E_{\text {opt }}$ the optical gap, $r=2$ is a number which characterizes the transition process and $B=4 \pi \sigma_{\min } / C n_{\mathrm{D}} \Delta E$ is the constant.

The reflectance was calculated using the equation

$$
t=(1-R)^{2} \exp (-A),
$$

where $R$ is the reflectance, $t$ the transmittance and $A$ the absorbance. The relation between optical dielectric constant, $\varepsilon^{\prime}$ and the square of the wavelength, $\lambda^{2}$, is given by

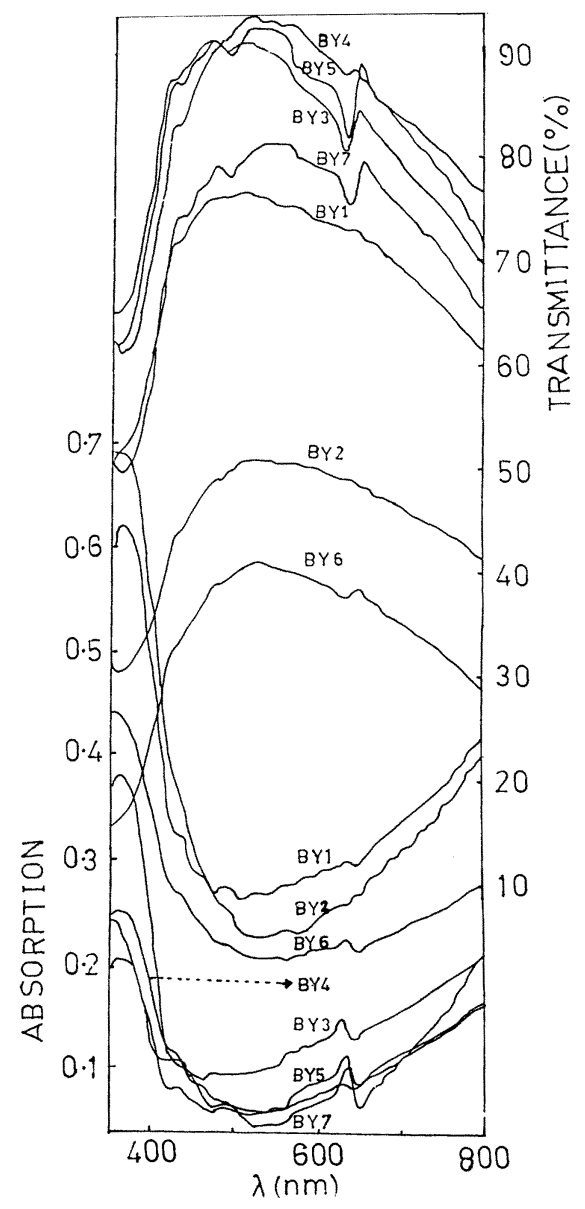

Figure 1. Spectral dependence of both absorption and transmittance vs $(\lambda)$.

$$
\begin{aligned}
\varepsilon^{\prime} & =n^{2}=\left[\frac{1+\sqrt{R}}{1+\sqrt{R}}\right]^{2} \\
& =\varepsilon_{\infty}^{\prime}-\frac{e^{2}}{\pi C^{2}} \frac{N}{m^{*}} \lambda^{2},
\end{aligned}
$$

where $\varepsilon_{\infty}^{\prime}$ is the dielectric constant at infinite high frequency, $e$, the electronic charge and $\mathrm{N} / \mathrm{m}^{*}$ the ratio of carrier concentration to the effective mass.

\section{Results and discussion}

Figure 2 shows the plots $(\alpha h v)^{1 / 2}$ vs $h v$ for different compositions of glass samples. The most satisfactory representation is obtained by plotting the quantity $(\alpha h v)^{1 / 2}$ as a function of $h \mathrm{v}$. Similar behaviour was also observed by other workers (Rashed and Ghani Salem 1984). The observed behaviour suggests forbidden indirect transition for some glassy and amorphous materials. The values of optical energy gap, $E_{\text {opt }}$, obtained from the extrapolation of the linear region and constant, $B$, from the slopes of the derived curves are shown in table 1 .

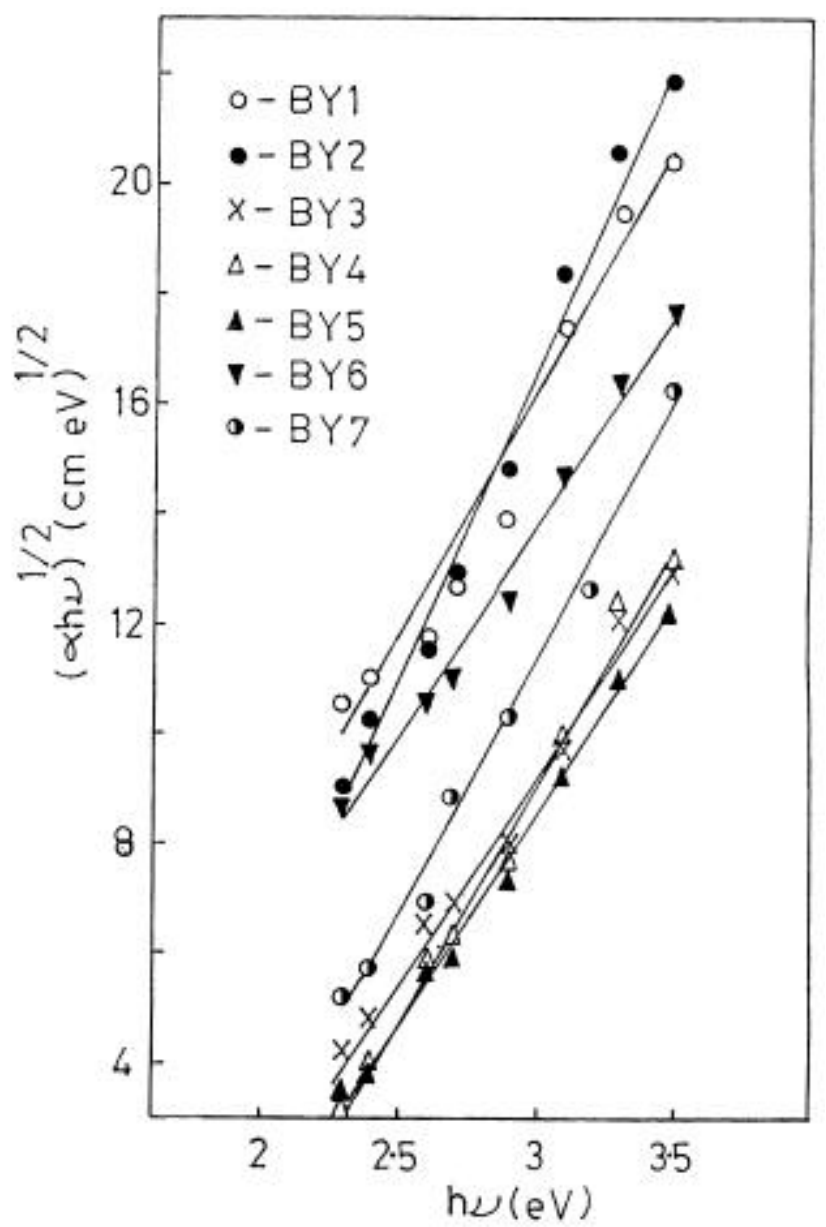

Figure 2. $(\alpha h v)^{1 / 2}$ vs $h v$ of glass samples. 
Table 1. Variation of optical energy gap $\left(E_{\mathrm{opt}}\right)$, infinitely high frequency dielectric constant $\left(\varepsilon_{\infty}^{\prime}\right)$, refractive index $\left(n_{\mathrm{D}}\right)$, constant $(B)$, measure of the extent of band tailing $(\Delta E)$ and the ratio of carrier concentration to the effective $N / m^{*}$ with different glass compositions.

\begin{tabular}{|c|c|c|c|c|c|c|c|c|c|}
\hline \multirow{2}{*}{$\begin{array}{l}\text { Sample } \\
\text { no. }\end{array}$} & \multicolumn{3}{|c|}{$\begin{array}{l}\text { Glass composi- } \\
\text { tion }(\mathrm{mol} \%)\end{array}$} & \multirow{2}{*}{$\begin{array}{c}\text { Optical } \\
\text { gap, } \\
E_{\text {opt }}(\mathrm{eV})\end{array}$} & \multirow{2}{*}{$\begin{array}{l}\text { Measure of extent } \\
\text { of band tailing } \\
(\Delta E)(\mathrm{eV})\end{array}$} & \multirow{2}{*}{$\begin{array}{c}\text { Dielectric } \\
\text { constant at } \\
\text { infinite frequency } \\
\left(\varepsilon_{\infty}^{\prime}\right)\end{array}$} & \multirow{2}{*}{$\begin{array}{l}\text { Refractive } \\
\text { index } \\
\left(n_{\mathrm{D}}\right)\end{array}$} & \multirow{2}{*}{$\begin{array}{c}\text { Constant, } \\
B \\
\left(\mathrm{~cm}^{-1} \mathrm{eV}^{-1 / 2}\right)\end{array}$} & \multirow{2}{*}{$\begin{array}{l}\text { Ratio of carrier concen- } \\
\text { tration to the effective } \\
\quad N / m^{*}\left(10^{21} \mathrm{~cm}^{-3}\right)\end{array}$} \\
\hline & $\mathrm{PbO}$ & $\mathrm{CuO}$ & $\mathrm{Bi}_{2} \mathrm{O}_{3}$ & & & & & & \\
\hline BY1 & $47 \cdot 5$ & $2 \cdot 5$ & 50 & $1 \cdot 50$ & $0 \cdot 25$ & $2 \cdot 15$ & $1 \cdot 30$ & $80 \cdot 00$ & 0.64 \\
\hline BY2 & $45 \cdot 0$ & $5 \cdot 0$ & 50 & 1.78 & $0 \cdot 25$ & $4 \cdot 80$ & $2 \cdot 66$ & 123.00 & 0.51 \\
\hline BY3 & $42 \cdot 5$ & $7 \cdot 5$ & 50 & $2 \cdot 18$ & $0 \cdot 37$ & $3 \cdot 25$ & 1.39 & 73.00 & $1 \cdot 22$ \\
\hline BY4 & $40 \cdot 0$ & $10 \cdot 0$ & 50 & $2 \cdot 32$ & 1.44 & $3 \cdot 50$ & 1.46 & $87 \cdot 46$ & $1 \cdot 19$ \\
\hline BY5 & $37 \cdot 5$ & $12 \cdot 0$ & 50 & $2 \cdot 30$ & 0.95 & $4 \cdot 25$ & 1.53 & $87 \cdot 89$ & 1.63 \\
\hline BY6 & $35 \cdot 0$ & $15 \cdot 0$ & 50 & 1.60 & $0 \cdot 46$ & $9 \cdot 60$ & 4.03 & $56 \cdot 25$ & $2 \cdot 67$ \\
\hline BY7 & $30 \cdot 0$ & $20 \cdot 0$ & 50 & $2 \cdot 10$ & $1 \cdot 24$ & $4 \cdot 15$ & 1.94 & 88.79 & 1.06 \\
\hline
\end{tabular}

The extrapolated d.c. electrical conductivity, $\sigma_{\min }$ at $t=\infty$ is obtained from the plot of $\log \sigma$ vs $1 / T$ (plot not shown). The values obtained for $E_{\mathrm{opt}}$ for the seven different compositions of glass samples are found to be nonlinear. Similar trends are observed in As-S, Ge-Se, AsSe and Ag-As glassy systems investigated by Hajto et al (1993).

The dielectric constant $\varepsilon^{\prime}$ vs $\lambda^{2}$ plots shown in figure 3 are linear, verifying (3). Values of $\varepsilon_{\infty}^{\prime}$ and $N / m^{*}$ determined from the extrapolation of these plots at $\lambda^{2}=0$ and the values of the ratio of carrier concentration to effective mass are listed in table 1 as functions of glass composition. The dependence of refractive index and dielectric constant on composition of glasses is rather non-linear and is observed to be similar to other amorphous materials (Hajto et al 1993). The values of refractive index, $n_{\mathrm{D}}$, are calculated from optical dielectric constant, $\varepsilon^{\prime}$, for all the wavelengths of $\lambda^{2}$. These values are found to be more or less the same through the wavelength range (350$800 \mathrm{~nm})$. Therefore, average values of $n_{\mathrm{D}}$ are reported in this wavelength region. The average value of refractive index, $n_{\mathrm{D}}$, shows dependence on $\mathrm{PbO}$ composition.

The variation of $\Delta E$, the width of the tail of localized states in the normally forbidden gap against $\mathrm{PbO}(\mathrm{mol} \%)$ is shown in figure 4 . The optical energy gap, $E_{\mathrm{opt}}$, is found to be minimum for the glass sample having 47.5 (mol\%) of $\mathrm{PbO}$ and $\Delta E$ for 47.5 and 45 (mol\%) of $\mathrm{PbO}$. The decreasing trend of the band tailing energy suggests the presence of sharp localized states in the band gap. The ratio of carrier concentration to the effective mass, $N / m^{*}$ has been calculated from the slope of the plot $\varepsilon^{\prime}$ vs $\lambda^{2}$ (figure 3). The value of $N / m^{*}$ for different glass samples (table 1) are found to be of the order of $10^{21} \mathrm{~cm}^{-3}$ which are in agreement with the values reported by other workers for oxide glasses (Ghosh and Chaudhari 1986) and calculated by other methods.

\section{Conclusions}

The optical gap $\left(E_{\text {opt }}\right)$ and band tailing factor $(\Delta E)$ are found to be compositionally dependent on $\mathrm{PbO}$ and $\mathrm{CuO}$.

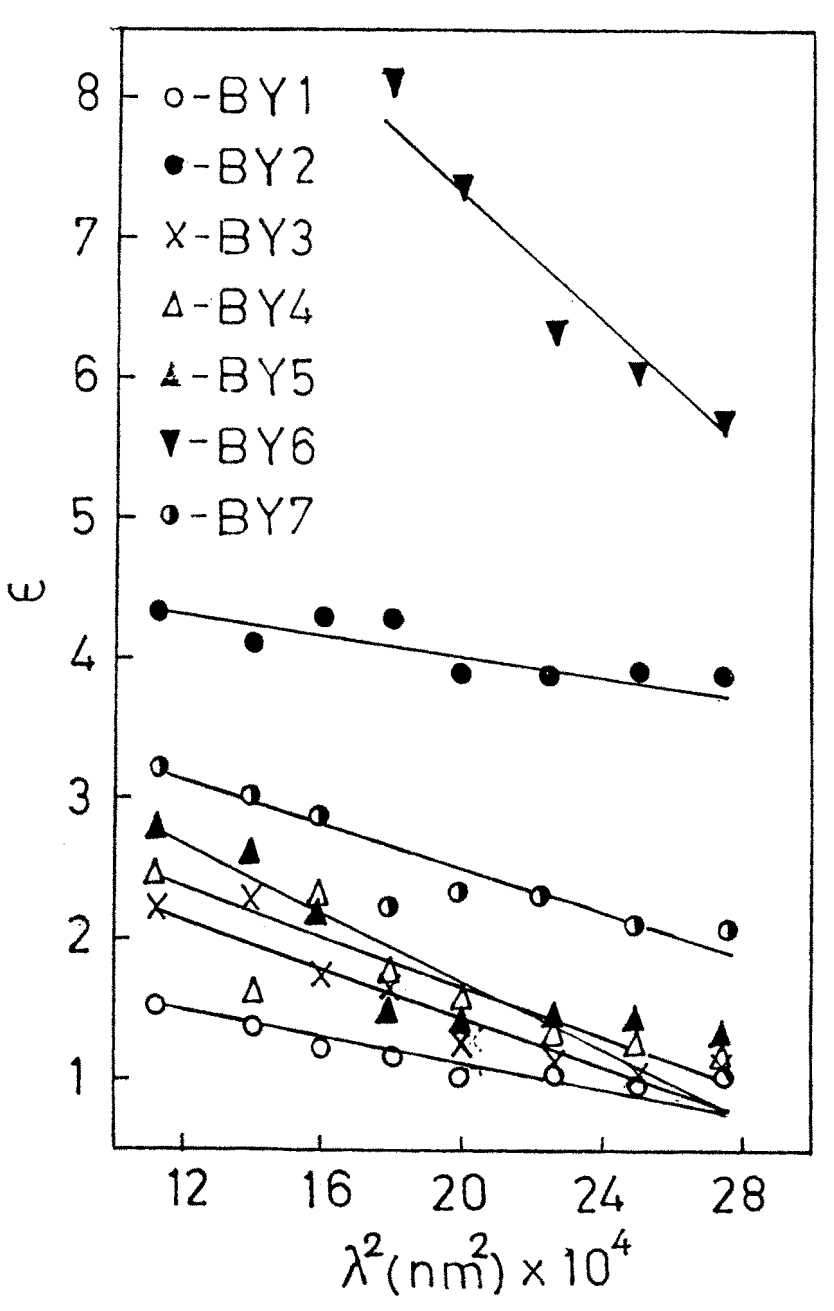

Figure 3. Dielectric constant vs $\lambda^{2}$.

The refractive index $\left(n_{\mathrm{D}}\right)$ calculated in the region 350$800 \mathrm{~nm}$ is found to be increasing with increasing content of $\mathrm{CuO}$ except for the glass compositions, 5 and 15 $(\mathrm{mol} \%)$ of $\mathrm{CuO}$. Non-linear behaviour is observed in the measure of extent of band tailing $(\Delta E)$ and optical gap $\left(E_{\text {opt }}\right)$. The ratio of carrier concentration to the effec- 


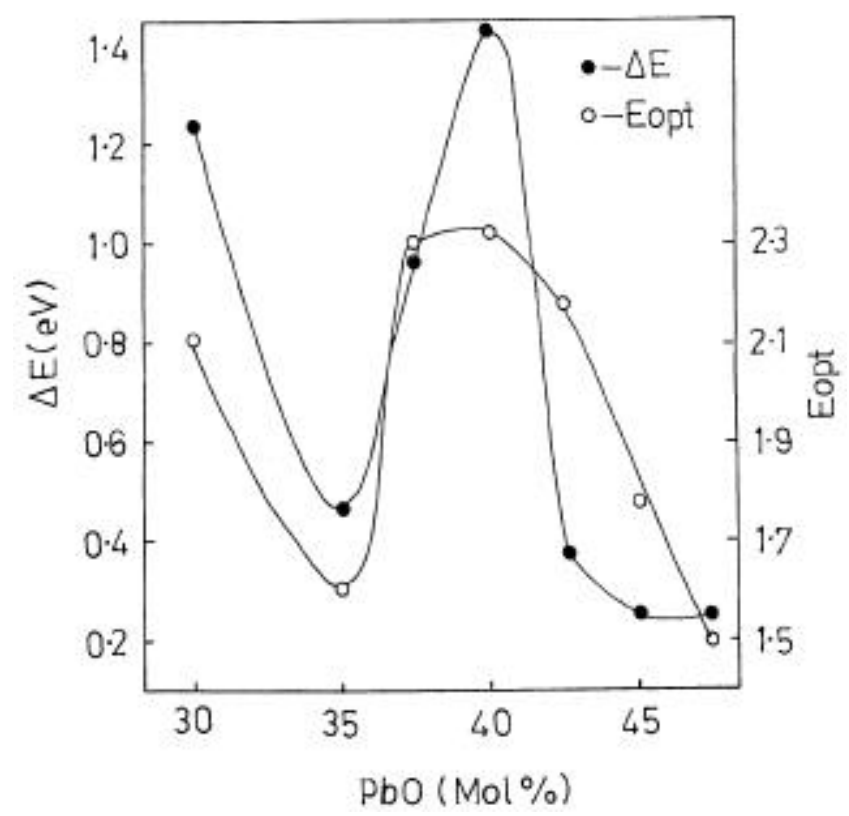

Figure 4. Optical energy gap, $E_{\mathrm{opt}}$ and band tailing energy, $\Delta E$ vs composition ( $\mathrm{PbO} \mathrm{mol} \%$ ).

tive mass $N / m^{*}$ is found to be of the order $10^{21}\left(\mathrm{~cm}^{-3}\right)$. The straight line behaviour in figure 2 suggests forbidden indirect transition.

\section{Acknowledgement}

Authors wish to thank Prof. V G Bhamburkar, Principal, Shri Shivaji Science College, Amravati, for providing necessary laboratory facilities during the course of this work.

\section{References}

Bishnoi N B, Sharma Y K, Surna S S N and Tanden S P 1993 Synth. Mater. 55469

Burghate D K, Deogaonkar V S, Pakade S V and Yawale S P 1995 Indian J. Pure Appl. Phys. 33683

Guomei W, Yuan W and Baohui J 1994 Proc. SPIE (Bellinghan, USA: International Society for Optical Engineering) p. 214

Gongyi G and Yuli C 1993 Mater. Chem. Phys. 3549

Ghosh A and Chaudhari B K 1986 J. Non-Cryst. Solids 83151

Hajto E, Ewen P J S and Owen A E 1993 J. Non-Cryst. Solids 164901

Janewicz M, Kopczyynnski K and Mierzyk Z 1993 Proc. SPIE (Bellinghan, USA: International Society for Optical Engineering) pp 1793, 158

Kentaro T, Hoon K S and Toshinobu Y 1995 J. Am. Ceram. Soc. 781601

Mandal S and Ghosh A 1993 Phys. Rev. B (Cond. Matter) 48388

Ma H L, Zhang X H and Lucas J 1993 J. Non-Cryst. Solids 161128 Memon A, Khan M N A I, Dalal S and Tanner D B 1993 Proc. SPIE (Bellinghan, USA: International Society for Optical Engineering)

Rashed I H and Ghani Salem A B D E I 1984 Indian J. Pure Appl. Phys. 22185 